Joel S. Baden

\title{
J, E, and the Redaction of the Pentateuch
}

[J, E, und die Redaktion des Pentateuch.]

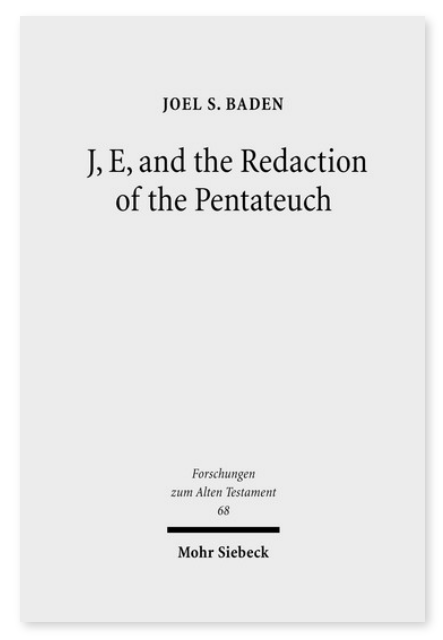

2009. XI, 339 Seiten. FAT 68

ISBN 978-3-16-151109-7

DOI 10.1628/978-3-16-151109-7

eBook PDF 129,00€

ISBN 978-3-16-149930-2

Leinen $129,00 €$
Veröffentlicht auf Englisch.

Joel S. Baden untersucht den Zusammenhang zwischen den Quellenschichten J und E im Pentateuch. Er zeigt, dass, entgegen der weitläufigen Meinung der klassischen Quellenkritik, die J und E Quellen nie zu einem 'JE' Dokument zusammengeführt wurden. Vielmehr wurden diese zwei Quellen in einem redaktionellen Prozeß zur selben Zeit miteinander kombiniert wie sie mit den P und D Dokumenten kombiniert wurden.

Der Autor stellt im Laufe der Studie mehrere wichtige Fragen in Bezug auf die Abfassung des Pentateuchs. Er untersucht die Existenz von E, den Zusammenhang zwischen D und den Erzählungen von Genesis und Numeri sowie das Anliegen des Redakteurs. Letztendlich stellt die Studie eine Kritik der traditionellen Dokumentationsanalyse des Pentateuchs einerseits und eine Verteidigung ihrer fundamentalen Behauptungen andererseits dar.

Joel S. Baden Born 1977; 2002 M.A. in Northwest Semitics from the University of Chicago; 2007 PhD in Hebrew Bible from Harvard University; currently Assistant Professor of Old Testament at the Yale Divinity School.

Jetzt bestellen:

https://mohrsiebeck.com/buch/j-e-and-the-redaction-of-the-pentateuch-9783161511097?no_cache=1

order@mohrsiebeck.com

Telefon: +49 (0)7071-923-17

Telefax: +49 (0)7071-51104 